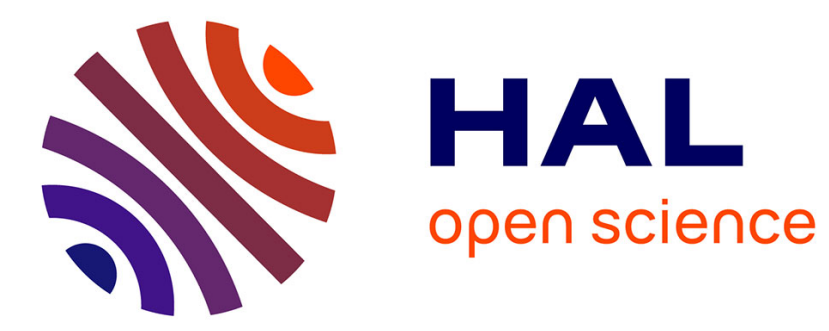

\title{
Influence of composition and distribution of the reinforcing particles on fatigue properties of metal matrix composites
}

\author{
E. Hochreiter, F. Jeglitsch
}

\section{- To cite this version:}

E. Hochreiter, F. Jeglitsch. Influence of composition and distribution of the reinforcing particles on fatigue properties of metal matrix composites. Journal de Physique IV Proceedings, 1993, 03 (C7), pp.C7-1763-C7-1767. 10.1051/jp4:19937279 . jpa-00251920

HAL Id: jpa-00251920

https://hal.science/jpa-00251920

Submitted on 1 Jan 1993

HAL is a multi-disciplinary open access archive for the deposit and dissemination of scientific research documents, whether they are published or not. The documents may come from teaching and research institutions in France or abroad, or from public or private research centers.
L'archive ouverte pluridisciplinaire HAL, est destinée au dépôt et à la diffusion de documents scientifiques de niveau recherche, publiés ou non, émanant des établissements d'enseignement et de recherche français ou étrangers, des laboratoires publics ou privés. 


\title{
Influence of composition and distribution of the reinforcing particles on fatigue properties of metal matrix composites
}

\author{
E. HOCHREITER and F. JEGLITSCH
}

Institut für Metallkunde und Werkstoffprüfung, Montanuniversität, Franz-Josef Strasse 18, 8700 Leoben, Austria

\begin{abstract}
Fatigue-life-time behaviour has been examined of extruded 6061 aluminium alloy composites reinforced with $15 \mathrm{vol} \% \mathrm{SiC}$ and 10 vol. $\% \mathrm{Al}_{2} \mathrm{O}_{3}$ particles. The peak particle sizes are at about 4.5 and $6 \mu \mathrm{m}$. Within measured $\mathrm{S}-\mathrm{N}$ curves the fatigue life-time at given stress amplitudes of $\mathrm{SiC}_{\mathrm{p}} / \mathrm{AA} 6061$ is superiour to that of $\mathrm{Al}_{2} \mathrm{O}_{3} / \mathrm{AA} 6061$ in the low-cycle fatigue region as well as in the high-cycle fatigue region. The discussion of these results has been done by means of theoretical evaluated crack propagation curves. Interfacial bonding has been studied by means of TEM investigations.
\end{abstract}

\section{Introduction}

Aluminium metal matrix composites are attractive because of their improved strength, stiffness, creep behaviour, wear resistance and low thermal expansion compared with the corresponding monolithic alloys [1-5]. Property improvement in fibre-or whisker-reinforced material is generally anisotropic, whereas particle reinforcement, although providing less efficient reinforcement than fibres or whiskers, has the advantage of producing a more or less isotropic composite material. Particulate reinforced MMCs are easier to produce using standard metallurgical processing such as powder metallurgy, direct casting, rolling, forging and extrusion. Furthermore, they can be shaped, machined and drilled using conventional metal fabrication facilities [6].

Within the European COST 506 action "Industrial Application of Light Metal Alloys" $\mathrm{SiC}$ - and $\mathrm{Al}_{2} \mathrm{O}_{3}$-particle-reinforced aluminium alloys are systems of interest. In this study, the fatigue strength of these composites is examined by Wohlertests. The role of the microstructure in influencing fatigue crack propagation behaviour is discussed, transforming the measured S-N curves to crack propagation curves.

\section{Experimental Procedure}

\section{Materials and Microstructure}

Two materials have been investigated in the course of this work: Aluminium alloy 6061 (AlMgSiCu) matrix reinforced with SiC particles $\left(\mathrm{SiC}_{\mathrm{p}}\right)$ with an average particle size of $4.5 \mu \mathrm{m}$ and a volume contents of $15 \%$ and $\mathrm{AA} 6061$ reinforced with $\mathrm{Al}_{2} \mathrm{O}_{3}$ particles $\left(\mathrm{Al}_{2} \mathrm{O}_{3} \mathrm{p}\right)$ with an average particle size of $6.0 \mu \mathrm{m}$ and a volume contents of $10 \% . \mathrm{SiC}_{\mathrm{p}}$ reinforced AA6061 ( $\left.\mathrm{SiC}_{\mathrm{p}} / \mathrm{AA} 6061\right)$ was fabricated by powder metallurgical processing, followed by hot extrusion. The $\mathrm{Al}_{2} \mathrm{O}_{3}$ p reinforced AA6061 ( $\mathrm{Al}_{2} \mathrm{O}_{3 \mathrm{p}} / \mathrm{AA} 6061$ ) was fabricated by casting methods, followed by hot extrusion. These extruded materials were subsequently solution heat treated at $525^{\circ} \mathrm{C}$ for 40 minutes, cold water quenched, aged for 24 hours at $160^{\circ} \mathrm{C}$ and furnace cooled (heat treatment T6). The optical micrographs of the cross section of the extruded and heat treated materials are shown in figures $\mathrm{la}$ and $\mathrm{lb}$. Despite of the obvious difference in size, shape and volume contents of particles, it is obvious that there is a tendency of clustering of the particles. The average particle size $d_{p}$, volume fraction $v_{p}$ and static properties of the investigated materials are shown in table 1 .
Tab. 1: Properties of the investigated materials

\begin{tabular}{ccccccc|c}
\hline material & $\begin{array}{c}\mathbf{d}_{\mathrm{p}} \\
{[\mu \mathrm{m}]}\end{array}$ & $\mathbf{v}_{\mathrm{p}}[-\mathbf{]}$ & $\begin{array}{c}\mathbf{R}_{\mathrm{p} 0.2} \\
{[\mathbf{M P a}]}\end{array}$ & $\begin{array}{c}\mathbf{R}_{\mathrm{m}} \\
{[\mathbf{M P a}]}\end{array}$ & $\begin{array}{c}\mathbf{A}_{5} \\
{[\%]}\end{array}$ & $\begin{array}{c}\mathbf{E} \\
{[\mathbf{G P a}]}\end{array}$ & $\alpha\left[\mathbf{K}^{-1}\right]$ \\
\hline $\mathrm{SiC}_{\mathrm{p}} / \mathrm{AA} 6061$ & 4.5 & 0.15 & 390 & 450 & 5.0 & 93 & \\
$\mathrm{Al}_{2} \mathrm{O}_{3 \mathrm{p}} / \mathrm{AA6061}$ & 6.0 & 0.10 & 341 & 389 & 7.0 & 85 & $20.9 \cdot 10^{-6}$ \\
$\mathrm{AA}_{6061}$ & - & - & 374 & 399 & 12.5 & 69 & $23.6 \cdot 10^{-6}$ \\
\hline $\mathrm{SiC}_{\mathrm{p}}$ & & & & & & & $4.02 \cdot 10^{-6}$ \\
$\mathrm{Al}_{2} \mathrm{O}_{3 \mathrm{p}}$ & & & & & & & $8.310^{-6}$ \\
\hline
\end{tabular}
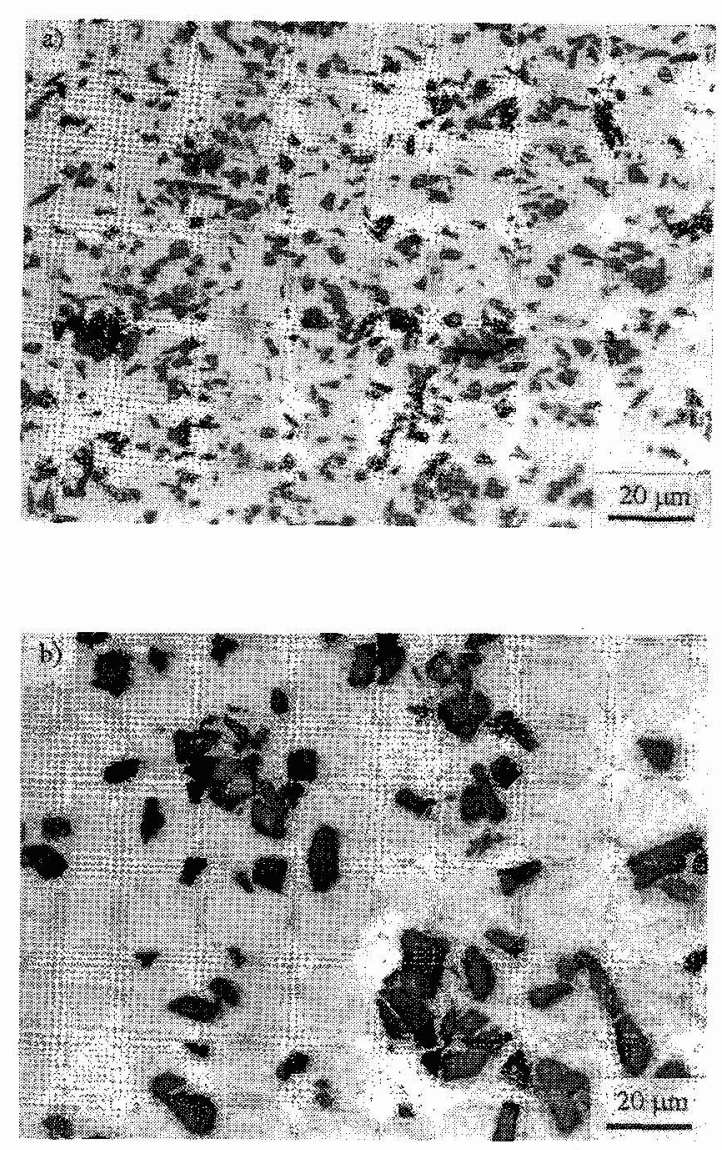

Fig.1: Optical micrographs of $\mathrm{SiC}_{\mathrm{p}} / \mathrm{AA} 6061$ (a) and $\mathrm{Al}_{2} \mathrm{O}_{3 \mathrm{p}} / \mathrm{AA} 606 \mathrm{I}$ (b) 


\section{Testing Methods}

As these materials in general show a rather brittle behaviour, a special shape has been developped for the fatigue test specimen to avoid that specimen will fail to a great extent beyond the gauge length. Fatigue tests were performed at room temperature in air on an axial $100 \mathrm{kN}$ push-pull Schenck PSA-S56 servohydraulic machine. The range of the stress amplitude $\sigma_{\mathrm{a}}$ has been varied between 90 and $350 \mathrm{MPa}$. The tests were carried out by using a sinusoidal wave form at adapted frequencies and a R-ratio of -1 . The endurance limit $\sigma_{e}$ is defined according to literature as the stress level at which a specimen does not fail until $5 \cdot 10^{7}$ cycles.

Fracture surfaces have been investigated by light optical microscope (LOM) and SEM methods. Furthermore TEM investigations of the interface particle-matrix have been done.

\section{Results}

\section{S- $N$ curves (Wöhler diagram)}

Figure 2 shows the S-N diagram in which the stress level $\sigma_{a}$ is plotted against the number of cycles to failure $\mathrm{Nr}$. To relate the curves for $\mathrm{SiC}_{\mathrm{p}} / \mathrm{AA} 6061$ and $\mathrm{Al}_{2} \mathrm{O}_{3}$ p/AA6061 the data for unreinforced material, produced by both production routes, are plotted in this diagram, too. As the matrix alloys did not show any difference in the measured fatigue properties, the same symbol has been used for both materials. On comparing the obtained data points, it is evident that there is a difference in endurance limits in such a way that the endurance limit of $\mathrm{Al}_{2} \mathrm{O}_{3 \mathrm{p}} / \mathrm{AA} 6061$ is comparable to that of AA6061 at $90-100$ $\mathrm{MPa}$, whereas the endurance limit is increased by a reinforcement with $\mathrm{SiC}$ particles to about $140 \mathrm{MPa}$. The difference between $\mathrm{SiC}_{\mathrm{p}} / \mathrm{AA} 6061$ and $\mathrm{Al}_{2} \mathrm{O}_{3 \mathrm{p}} / \mathrm{AA} 6061$ also appears in the low-cycle-fatigue region (LCF-region).

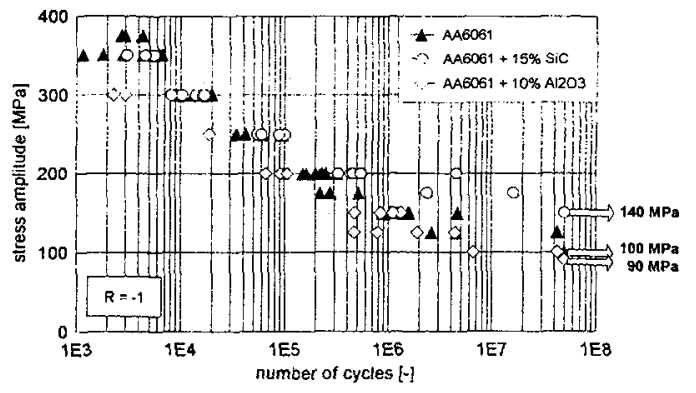

Fig.2: Measured S- $\mathrm{N}$ diagram

\section{Relationship between S-N and Crack Propagation Curve}

The S-N curve is a good means to design technical applications, but as it is not only characterised by the material it is no good means for the discussion of material behaviour. In general it depends on the constitution - in special the surface roughness and the geometry of the sample. This because fatigue life consists of crack initiation (No cycles) and crack propagation. As the constitution of the surface is related to the crack initiation process, it has a great influence on the overall fatigue life.

In fracture mechanics the stress in front of the crack tip is described by the stress intensity $\mathrm{K}$, which depends largely on the crack depth and the geometry of the specimen (equation (1)).
$\mathrm{Y}$ is a geometry factor, depending on the shape and the depth of the crack, $\Delta \sigma$ is the difference between the minimum and the maximum of the stress amplitude. If the crack propagation rate da/dN is plotted against $\Delta K$, one obtains a crack propagation diagram which does not take into account crack initiation. Crack propagation curves are limited by the threshold stress intensity level $\Delta K_{0}$ and the dynamic fracture thoughness $\Delta \mathrm{K}_{\mathrm{IC}}{ }^{\mathrm{d}}$. $\Delta \mathrm{K}_{0}$ is the stress intensity level below which cracks are stable, $\Delta \mathrm{K}_{\mathrm{IC}} \mathrm{d}$ is the stress intensity level beyond which a specimen will fail within one cycle of loading.

It is obvious that the LCF-region of the $\mathrm{S}-\mathrm{N}$ curve is related to the $\Delta \mathrm{K}_{\mathrm{IC}}{ }^{\mathrm{d}}$-region and that $\Delta \sigma_{\mathrm{e}}$ is correlated to $\Delta \mathrm{K}_{0}$. This correlation is expressed by equation (2).

$$
\Delta K_{t h}=\Delta \sigma_{e} \cdot \sqrt{\pi a 0} \cdot Y\left(a_{0}\right)
$$

For the investigated particle reinforced composites it seems to be correct to assume that greater particles or particle associations in the region near the surface represent the magnitude of the critical crack length ao at which cracks are able to grow. Although it will take part of fatigue life to debond or to crack these particles or particle associations, it can be assumed that cracks of the critical crack depth are already present before fatigue testing $\left(\mathrm{N}_{0}=0\right)$. The mathematical transformation equation, valid for stress amplitudes between the yield strength and $\sigma_{e}$, is given by equation (3).

$$
N_{f}-N_{0}=\int_{a_{0}}^{a_{f}} \frac{1}{\Delta a / \Delta N} \cdot \Delta a
$$

Within the crack-propagation diagram the corresponding linear, so-called Paris region, satisfies the following equation:

$$
\frac{d a}{d N}=C \cdot(\Delta K)^{m}
$$

( $C$ and $m$ are material parameters). The combination of equation (1), (3) and (4) leads to a transformation solution, which makes it possible to interpret measured $S-N$ data in values of $\Delta K$. This means, it is possible to discuss the material behaviour by means of measured S-N curves, assuming that critical cracks are present before starting fatigue testing.

\section{Discussion}

$\Delta K_{\text {th }}$ can be calculated by equation (2), assuming that the initial crack depth an is given by the particle size $\mathrm{d}_{\mathrm{p}}$. Due to the supposition that cracks are semielliptical surface cracks, the geometry factor $Y\left(d_{p}\right)$ can be set to one. In combination with the measured endurance limits $\Delta \mathrm{K}_{\mathrm{th}, \mathrm{p}}$ of $\mathrm{SiC}_{\mathrm{p}} / \mathrm{AA} 606 \mathrm{l}$ and $\mathrm{Al}_{2} \mathrm{O}_{3 \mathrm{p}} / \mathrm{AA} 6061$ are calculated to 0.78 and $1.05 \mathrm{MPa} \mathrm{m}^{1 / 2}$.

This seems to be the correct tendency as the lower endurance limit implies that crack growth starts at lower stress levels. A lower threshold stress intensity level is required for crack growth, due to the greater particle and hence crack size of $\mathrm{Al}_{2} \mathrm{O}_{3}$ /AA6061. But there exists some literature dealing with $\Delta \mathrm{K}_{\mathrm{th}}$ values for $\mathrm{SiC}_{\mathrm{p}} / \mathrm{AA6061}$ [1,7] which are in general two times higher than the calculated value of $1.05 \mathrm{MPam}^{2}$. If the assumptions, made to calculate these $\Delta \mathrm{K}_{\text {th }}$ values, are correct, this difference has to be caused by the initial crack length ao. Measurements of the overall particle and cluster size distribution pointed out that mean cluster sizes $\mathrm{d}_{\mathrm{c}}$ are at about $15 \mu \mathrm{m}$ for $\mathrm{SiC}_{\mathrm{p}} / \mathrm{AA} 6061$ and at about $30 \mu \mathrm{m}$ for $\mathrm{Al}_{2} \mathrm{O}_{3 \mathrm{p}} / \mathrm{AA} 6061$. Taking into account these cluster sizes, $\Delta \mathrm{K}_{\mathrm{th}, \mathrm{c}}$ values are calculated to $1.9 \mathrm{MPam}^{1 / 2}$ for $\mathrm{SiC}_{\mathrm{p}} / \mathrm{AA} 6061$ and $1.7 \mathrm{MPam}^{1 / 2}$ for $\mathrm{Al}_{2} \mathrm{O}_{3 \mathrm{p}} / \mathrm{AA} 6061$. As this is the expected range of the treshold stress intensity level, one has to stress that clusters of particles near the surface are the most probable sites of fatigue crack initiation. This has been verified by identifying the crack initiation sites by SEM investigations mainly as clusters or large particles (fig. 3 ).

$$
\Delta K=\Delta \sigma \cdot \sqrt{\pi a} \cdot Y(a)
$$



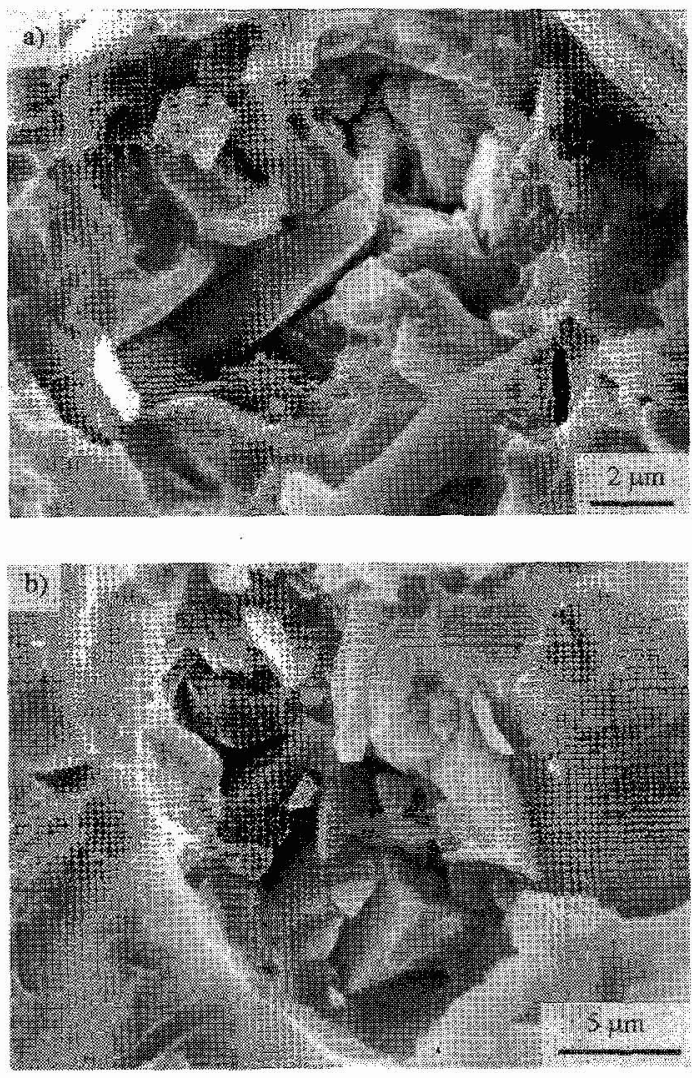

Fig.3: SEM pictures of fatigue crack initiation sites in SiCp/AA6061; (a) large SiC particle associated with $\mathrm{SiC}$ cluster; (b) $\mathrm{SiC}$ cluster

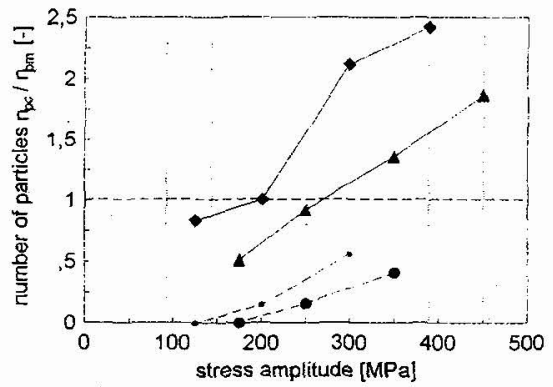

$\begin{array}{ll}\text { - SIC/A60B1 - particles } & - \text { Al2O3/A6061 - particles } \\ - \text { SIC/AG661-cracked particles } & - \text { AI2O3/A6061 - cracked particles }\end{array}$

Fig.4: Normalized number of particles within the fatigue crack path, dependent on the stress amplitude
In order to determine the role of the particles within the stable crack propagation process, the sites of fatigue crack initiation have been determined, marked and then the samples have been cut in the length section in a way that the cut sectiones the crack initiation site. The number of particles and the number of cracked particies involved in the crack path have been counted. The particle count took place till a crack depth of about $200 \mu \mathrm{m}$. The resuits have been normalized by the average particle count within the cross section in order to make it possible to compare the different volume fractions and particle size distributions. The normalized particle number within the crack path has been plotted against the stress amplitude $\sigma_{a}$ (fig. 4). The vertical dotted lines mark the endurance limit $\sigma_{e}$ and the tensile strength $\mathrm{R}_{\mathrm{m}}$ of $\mathrm{SiC}_{\mathrm{p}} / \mathrm{AA} 606 \mathrm{l}$ and $\mathrm{Al}_{2} \mathrm{O}_{3 \mathrm{p}} / \mathrm{AA} 6061$. The number of particles as well as the number of cracked particles increases drastically with increasing stress amplitude. The horizontal dashed line marks the average particle count. If the measured number of particles is below this line, there should be a tendency of the crack front to avoid particles; if it is above this line, the fatigue crack seems to propagate preferentially from particle to particle. Therefore, a change in the fatigue crack propagation mechanism takes place with increasing stress amplitude. In the case of $\mathrm{Al}_{2} \mathrm{O}_{3 \mathrm{p}} / \mathrm{AA} 6061$ this change should occur at lower stress amplitudes than with $\mathrm{SiC}_{\mathrm{p}} / \mathrm{AA} 6061$.

The stress intensity varies at a given stress amplitude with the crack depth (equation (1)). But as particle counting has been done within a limited crack depth, the mean stress intensity is related to the stress amplitude. Therefore, it should be possible to relate a stress intensity level to a certain stress amplitude.
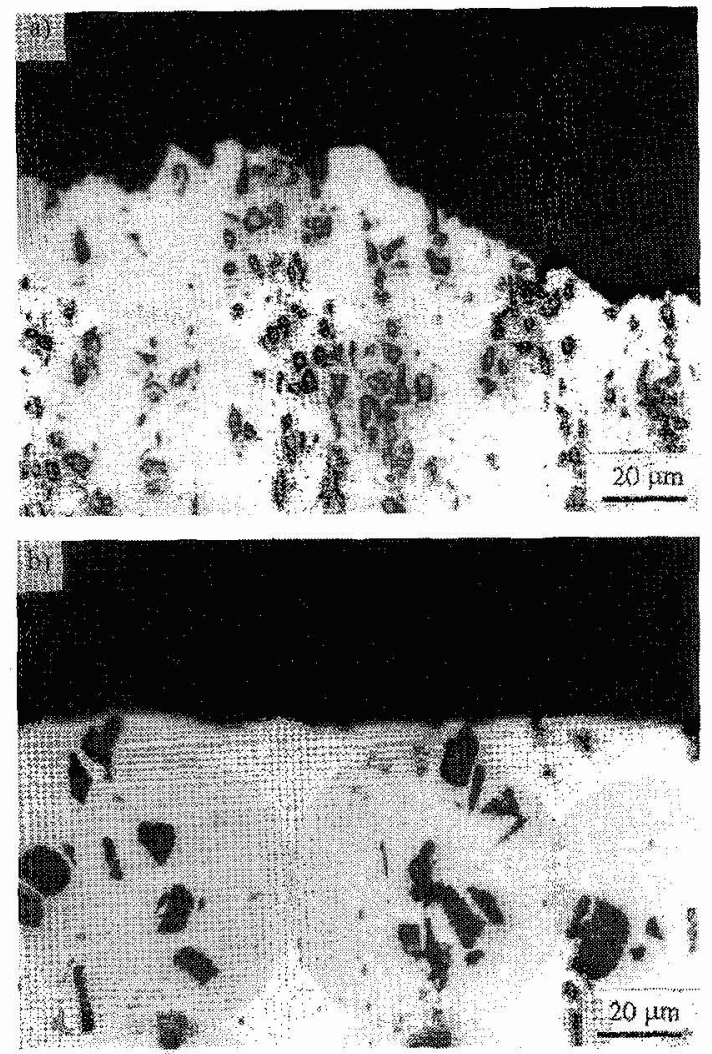

Fig.5: Optical micrographs of crack path profiles of $\mathrm{SiC}_{\mathrm{p}} / \mathrm{AA} 6061$ (a) and $\mathrm{Al}_{2} \mathrm{O}_{3 \mathrm{p}} / \mathrm{AA} 6061$ (b) at low stress amplitudes 
With this, the observations on the fatigue crack growth process were as follows: At low stress intensity levels (low stress amplitudes) the crack seems to be deflected from the particles to the matrix; nearly no cracked particles can be found within the fatigue crack path (fig. 5). This deflection could be caused by the interaction of the dislocations with the residual stresses around the particles, which are due to differences of the coefficiants of thermal expansion (tab. 1). At higher stress intensity levels (higher stress amplitudes) mainly the larger particles seem to be cracked or debonded ahead of the crack tip (fig. 6). These subcracks, on the one hand, cause crack bridging, which is one mechanism of crack tip shielding, one the other hand the linking of these subcracks by the fatigue crack leads to instable crack propagation, related to the $\Delta \mathrm{K}_{\mathrm{IC}} \mathrm{d}_{\mathrm{d}}$-region (the $\mathrm{LCF}$-region in the S-N diagram). The LOM picture (fig. 6) indicates a rougher fracture surface for $\mathrm{SiC}_{\mathrm{p}} / \mathrm{AA} 6061$ due to the finer particles and the higher volume contents. Surface roughness indicales crack closure mechanisms which lead to crack tip shielding, too [8]. Caused by these reasons, the crack propagation rate for $\mathrm{SiC}_{\mathrm{p}} / \mathrm{AA} 606 \mathrm{l}$ should be lower than that of $\mathrm{Al}_{2} \mathrm{O}_{3}$ p/AA6061. This perfectly suits the fact, that the $\mathrm{S}-\mathrm{N}$ curve for $\mathrm{Al}_{2} \mathrm{O}_{3} \mathrm{p} / \mathrm{AA} 6061$ is below that of $\mathrm{SiC}_{\mathrm{p}} / \mathrm{AA} 6061$ in the LCF-region.

It has been postulated that instable crack propagation is related to cracking or debonding of particles ahead of the crack tip. Cracking and debonding of particles depends on particle and interfacial strength. On the assumption that fracture of particles is (maximum principal) stress controlled, the "strength" $\mathrm{S}$ of each particle is roughly inversely proportional to the square root
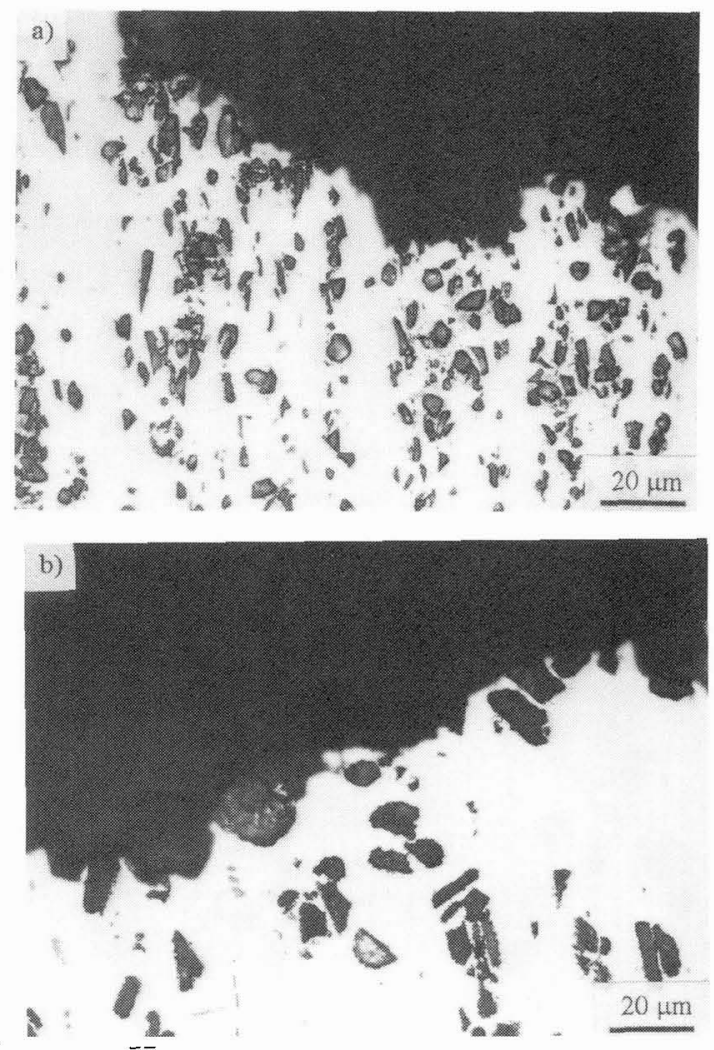

Fig.6: Optical micrographs of crack path profiles of $\mathrm{SiC}_{\mathrm{p}} / \mathrm{AA} 6061$ (a) and $\mathrm{Al}_{2} \mathrm{O}_{3 \mathrm{p}} / \mathrm{AA} 6061$ (b) at high stress amplitudes of its characteristic dimension $d_{p}[9,10]$. Obviously, for a hypothetical homogeneous tensile stress distribution the maximum propability of fracture is given for the largest particles. As the $\mathrm{Al}_{2} \mathrm{O}_{3}$ particles are larger than the $\mathrm{SiC}$ particles, the probabilty of fracture is higher at a certain tensile stress. This means, that $\mathrm{Al}_{2} \mathrm{O}_{3} \mathrm{p}$ will crack at lower stress amplitudes within a certain distance ahead of the crack tip.

TEM investigations of the particle-matrix interfaces revealed that no significant surface reaction zone exists at $\mathrm{SiC}$ particles (fig. 7a). Sometimes SiC particles show a facetted surface,maybe due to thermal etching effects, which should cause a mechanical interlocking of the particles. At $\mathrm{Al}_{2} \mathrm{O}_{3}$ particles a brittle AlMgO-spinel interface has been identified (fig. 7b). As the formation of these spinel cristals is caused by diffusion, the thickness of this spinel zone should be sensitive to the temperature treatment. SEM investigations of the final fracture surface (fig.8a) confirmed the good bonding of $\mathrm{SiC}$ particles. $\mathrm{Al}_{2} \mathrm{O}_{3}$ particles show the discussed surface reaction zone. Due to this reaction zone and to the low particle strength almost all $\mathrm{Al}_{2} \mathrm{O}_{3}$ particles are loosened and/or cracked within the final fracture surface (fig. 8 b).

This implies that instable crack growth - which is correlated to particle cracking ahead of the crack tip - will take place at lower tensile stress, this means at last at lower stress amplitudes (LCF-region; $\mathrm{a}=$ const.), compared with $\mathrm{SiC}_{\mathrm{p}} / \mathrm{AA6061}$. Therefore $\Delta K_{I C}{ }^{d}$ should be lower for $\mathrm{Al}_{2} \mathrm{O}_{3 \mathrm{p}} / \mathrm{AA} 6061$.

As final fracture is somewhere correlated to the LCF region, it is obvious that the $\mathrm{S}-\mathrm{N}$ curve of $\mathrm{Al}_{2} \mathrm{O}_{3 \mathrm{p}} / \mathrm{AA} 6061$ is below the one of $\mathrm{SiC}_{\mathrm{p}} / \mathrm{AA} 6061$.
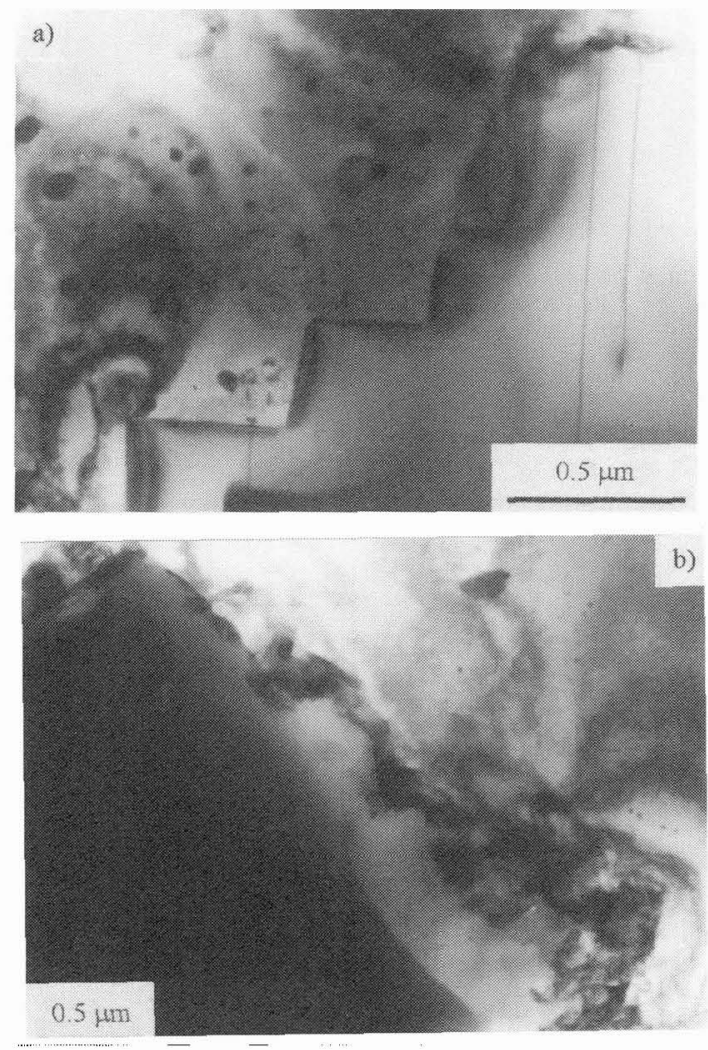

Fig.7: facetted surface of $\mathrm{SiC}_{\mathrm{p}}$ (a) and $\mathrm{AMMO}$-spinell interface at $\mathrm{Al}_{2} \mathrm{O}_{3 p}$ (b) 

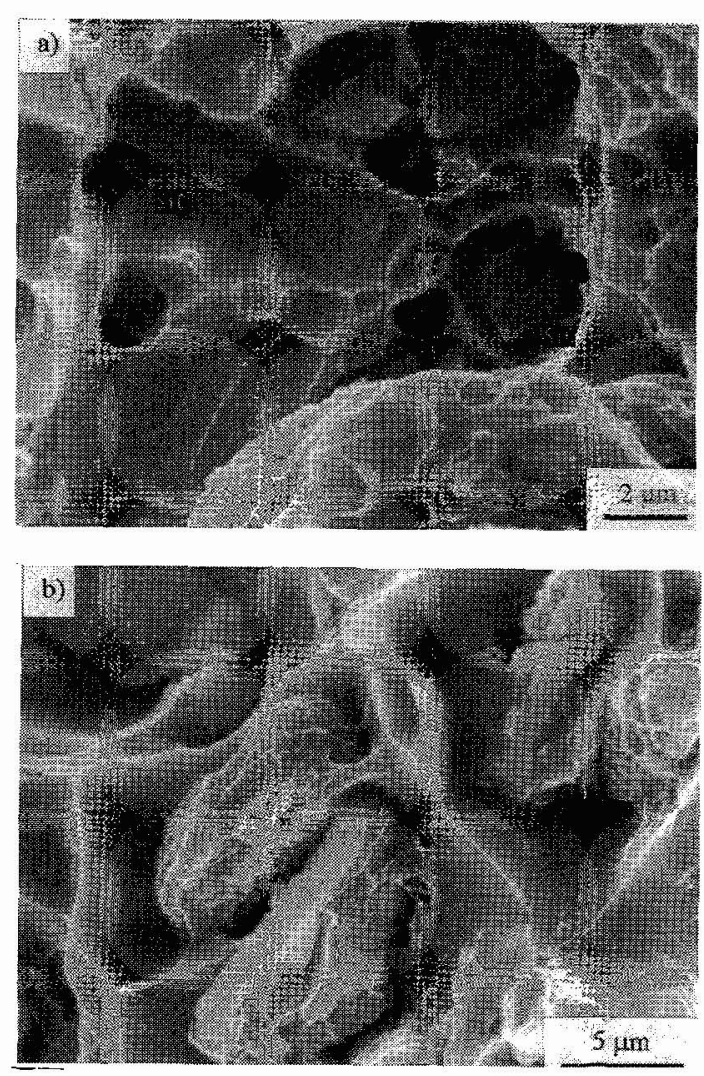

Fig.8: Final fracture surface of $\mathrm{SiC}_{\mathrm{p}} / \mathrm{AA} 6061$ (a) and $\mathrm{Al}_{2} \mathrm{O}_{3 \mathrm{p}} / \mathrm{AA6061}$ (b)

\section{Conclusions}

Based on investigations which revealed the role of $\mathrm{SiC}$ and $\mathrm{Al}_{2} \mathrm{O}_{3}$ particles during fatigue life at $\mathrm{R}=-1$ in extruded $\mathrm{AlMgSiCu}$ (AA6061) metal-matrix composites the following conclusions can be made:

The interaction of particles and the propagating fatigue crack is determined by the residual stress field in the particle near region and the strength of the interfacial bonding and the particles themselves. These quantities at last depend on chemistry, size and shape of the particles. In order to reduce the fatigue crack propagation rate crack closure mechanisms should be encouraged.

Although fatigue life time of aluminium alloys will be decreased in most cases by particle reinforcement, an improvement of fatigue properties can be expected if the compatibility and the size of the reinforcement are well selected. Furthermore the homogeneity of the particle distribution, which largely depends on the production route, determines the efficiency of the reinforcement.

\section{References}

[1] Shang, J.K, Yu, W. and Ritchie, R.O., Mater. Sci. Eng. A, 102 (1988) 181

[2] DiVecha, A.P., Fishman, S.G. and Karmarkar, S.D., J. Met.., 33 (1981) 12

[3] Arsenault, R.J., Mater. Sci. Eng., 64 (1984) 171

[4] Crowe, C.R., Gray, R.A. and Hasson, D.F. in Harrigan, W., Strife, J. and Dhingra, A.K. (eds.), Proc. 5 th Int. Conf. on Composite Materials, Metallurgical Society of AIME, Warrendale, PA, 1985, 843

[5] Nair, S.V., Tien, J.K. and Bates, R.C., Int. Metall. Rev, 30 (1985) 275

[6] Srivatsan, T.S., Auradkar, R., Lavernia, E.J. and Prakash, A., Mater. Trans, JIM, 32 (1991) 473

[7] Kumai, S., King, J.E., and Knott, J.F., Fatigue Fract. Engng. Mater. Struct., 13 (1990) 511

[8] Stanzl, S.E. in Munz, D. (ed.), Ermüdungsverhallen metallischer Werksioffe, DGM, Oberursel, Germany, 1984 , 107

[9] Lin, T., Evans, A.G. and Ritchie, R.O., Metall. Trans. $A, 18$ (1987) 641

[10] Curry, D. and Knott, J.F., Met. Sci., 12 (1978) 511

[11] Berek, H., Zywitzki, O., Degischer, H.P. and Leitner, H. in Lopez Galindo, A. and Rodriguez Garcia, M.I (eds.), Proc. 10th Eur. Congr. Electr. Microscopy, Granada, 2 (1992), 695 